\title{
Macrocyclic nickel complexes in DNA recognition and oxidation
}

\author{
J. G. Muller, X. Chen, A. C. Dadiz, S. E. Rokita* and C. J. Burrows* \\ Department of Chemistry, State University of New York at Stony Brook, Stony Brook, \\ NY 11794-3400
}

\begin{abstract}
Nickel(II) macrocyclic complexes have been found to promote site- and conformation-specific oxidation of DNA. The systematic study of ligand effects has demonstrated that the crucial features in regulating DNA reactivity are in-plane donor strength and flexibility of the macrocyclic ligand. Based upon investigations of conformation specificity, macrocyclic ligand effects, and oxidant requirements, a mechanism has been proposed. In this mechanism, a nickel(III) complex containing a ligated guanine and oxidant molecule is postulated as a key intermediate. The oxidation of DNA has also been extended to macrocyclic complexes containing cobalt(III), rhodium(III) and chromium(III).
\end{abstract}

\section{INTRODUCTION}

An important feature associated with the development of DNA modification agents has been the use of transition metal complexes that can specifically recognize and cleave DNA (refs. 1 and 2). In the majority of the complexes studied the metal ion serves as the oxidation agent while the ligand is responsible for DNA recognition. The modes of recognition are primarily based upon intercalation, groove-binding and hydrogenbonding interactions (ref 2). Site-specific DNA modification has also been observed for transition complexes that are covalently linked to DNA-binding proteins (ref. 3). In contrast, platinum chemotherapeutic agents such as cis- $\mathrm{Pt}\left(\mathrm{NH}_{3}\right)_{2} \mathrm{Cl}_{2}$ (cis-platin) interact specifically with duplex DNA by forming covalent bonds between the platinum metal center and N7 of guanine (refs. 4 and 5). The mode of action of cis-platin is believed to involve the replacement of the two labile chloride ions with guanine resulting in intrastrand cross-links.

In our laboratories nickel(II) macrocyclic complexes have been investigated as potential site-specific DNA modification agents. Square planar nickel(II) complexes were studied owing to their known catalytic activity towards olefin epoxidation. Nickel macrocyclic complexes that possess vacant or labile coordination sites may also ligate to DNA bases, and effect site-specific reactions with DNA. Interestingly, a series of nickel(II) square planar complexes 5, 8 and 9 (Fig. 1), in the presence of potassium monopersulfate $\left(\mathrm{KHSO}_{5}\right.$ ) or magnesium monoperoxyphthalate (MMPP), induced guanine-specific modification of single-stranded oligonucleotides leading to strand scission after treatment with piperidine (ref. 6 ).

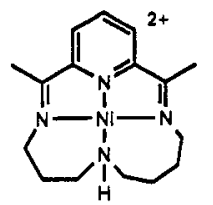

1<smiles>CC1=C(C)[N+]23N4CCCN(C1)N2CCCN3CC4</smiles>

9

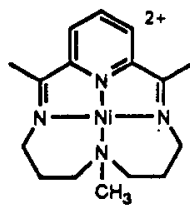

2

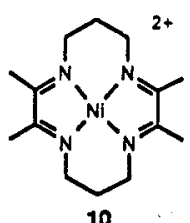

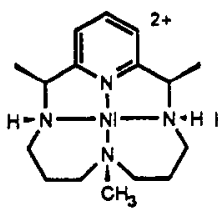

3

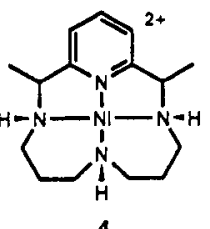

4

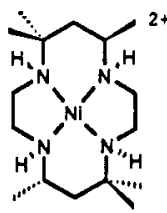

12

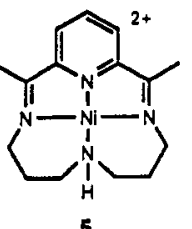

5

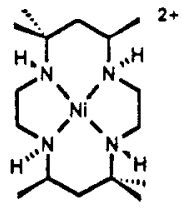

13
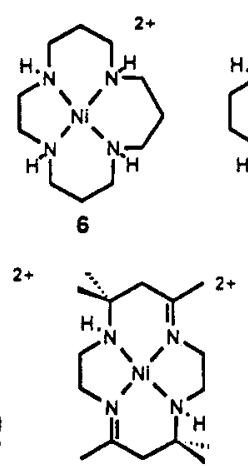

14

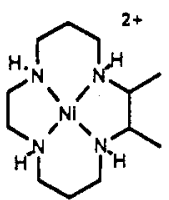

7

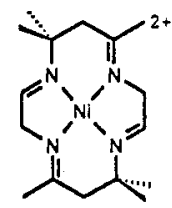

15

Fig. 1. Nickel(II) complexes employed in the study of DNA oxidation. 
A dependence upon the physical properties of the macrocyclic ligand was observed, and initial studies suggested the important factors to be ( $i$ ) the availability of vacant coordination sites, (ii) the overall charge of the coordination complex, and (iii) the redox potential associated with the $\mathrm{Ni}^{\mathrm{II} / 11}$ redox couple. Thus, our current attention has focused upon probing the conformation- and site-specific oxidation associated with nickel(II) macrocyclic complexes (ref. 7). Furthermore, the mechanistic aspects have been examined through a systematic study of effects associated with the macrocyclic ligand (ref. 8), the oxidant, and the central metal atom.

\section{CONFORMATION-SPECIFIC OXIDATION OF DNA}

\section{Application of nickel complexes to DNA structural analysis}

In order to investigate the conformational selectivity of nickel(II) macrocyclic complexes towards the guaninespecific oxidation of DNA a series of oligonucleotides (Fig. 2) containing mispaired, bulged, looped, terminal or Watson-Crick base-paired guanine residues were examined (ref. 7). Complex 5 was shown to promote the oxidation of all guanine residues in single-stranded oligonucleotides, while guanine residues present within the interior of a Watson-Crick double helix (A) proved to be unreactive. Conversely, complex $\mathbf{5}$ readily modified guanine residues present at the terminus of $\mathbf{A}$ and in non-classical hydrogen bonding pairs such as at guanineguanine mismatches (B). Complex 5 has also proved useful in detecting highly accessible guanine sites such as those found in oligonucleotide bulges (C) and loops (D and E). The observed conformation specificity in oligonucleotides using complex $\mathbf{5}$ is likely the result of steric requirements associated with the direct ligation of nickel to N7 of guanine, whereby the terminal, mismatched, bulged, or looped guanine residues provide an accessible coordination site for the nickel complex.

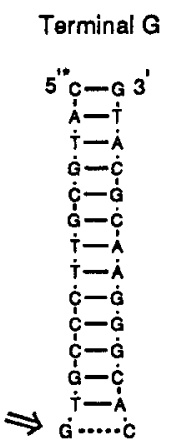

A

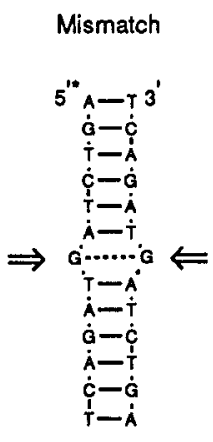

B

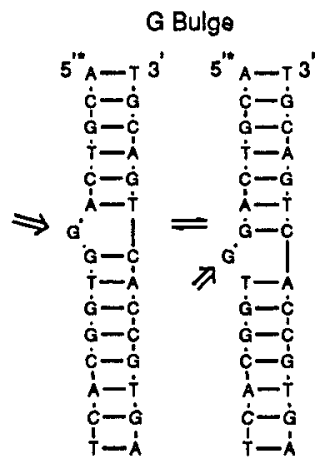

c
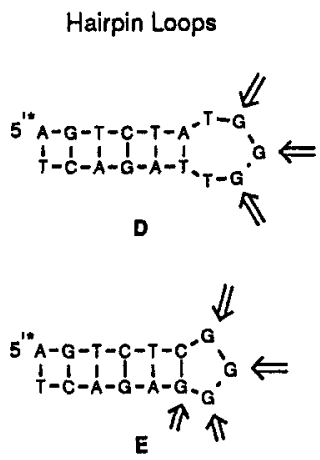

Fig. 2. DNA structures recognized by complex 5 .

\section{Comparison of chemical nucleases}

The specificity of nickel complex $\mathbf{5}$ was compared to other common chemical nucleases in order to rule out hyperreactivity of unpaired guanine residues as a cause of specificity. As demonstrated in Fig. 3, complex 5 was found to be much more selective for guanine residues present in a hairpin loop (oligonucleotide D) as compared to either $[\mathrm{Fe}(\mathrm{EDTA})]^{2-},[\mathrm{Mn}(\mathrm{TMPP})]^{5+}$, dimethyl sulfate or $\left[\mathrm{Cu}(\mathrm{phen})_{2}\right]^{2+}$. The non-specific reactivity of [Fe(EDTA)] $]^{2-}$ towards oligonucleotide $\mathbf{D}$ is consistent with the proposed mechanism, which is believed to involve the formation of freely diffusible hydroxyl radicals (ref. 9). In contrast, the complexes [MA(TMPP)] ${ }^{5+}$ and $\left[\mathrm{Cu}(\text { phen })_{2}\right]^{2+}$ which possess ligands that interact with DNA displayed a weak selectivity for oxidation of oligonucleotide $\mathbf{D}$. The cleavage pattern of $[\mathrm{Mn}(\mathrm{TMPP})]^{5+}$ is consistent with the observations of Meunier (ref. 10 ), in which an enhanced reactivity of guanine residues was detected in TG or AG sequences. The sequenceselectivity of this complex has been attributed to its electrostatic or intercalative binding to DNA followed by oxidation which may involve an oxo manganese species. In the case of $\left[\mathrm{Cu}(\mathrm{phen})_{2}\right]^{2+}$ (ref. 11) enhanced reactivity was observed at duplex regions of the hairpin oligonucleotide. The increased modification of duplex versus looped regions has been previously reported by Drew and was attributed to intercalation of [Cu(phen $\left.)_{2}\right]^{2+}$ between base-pairs, followed by diffusion of radicals to nearby deoxyribose residues (ref. 12). Finally, dimethyl sulfate which functions as a guanine-specific alkylation agent, modified both base-paired and unpaired guanine residues. This well characterized reaction involves methylation of $\mathrm{N} 7$ of guanine followed by strand scission upon treatment with piperidine (ref. 13). While both complex 5 and dimethyl sulfate are believed to involve bonding to N7 of guanine, the steric bulk of the macrocyclic ligand is believed to limit reactivity of complex 5 to only those guanine residues that are readily accessible. This property makes $\mathbf{5}$ a unique and useful structural probe of DNA and RNA. 

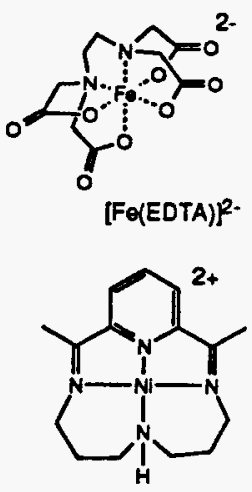

5
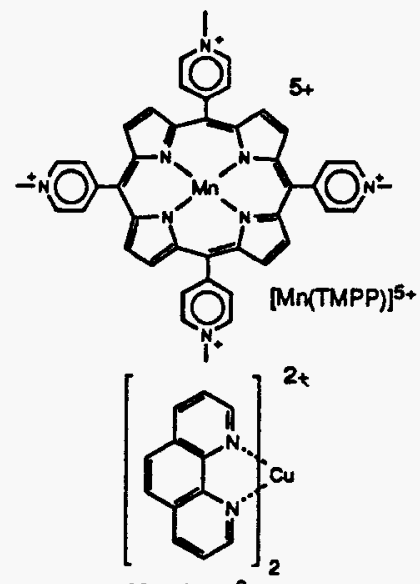

[Cu(phen) $\}^{2+}$

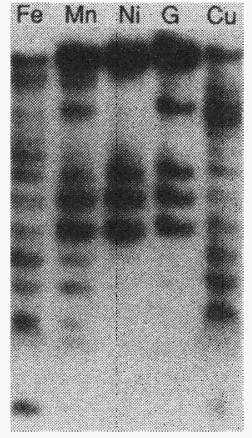

Fig. 3. Comparison of chemical nucleases after alkaline treatment. Modification of oligonucleotide $\mathbf{D}$ by $[\mathrm{Fe}(\mathrm{EDTA})]^{2-}(\mathrm{Fe}),[\mathrm{Mn}(\mathrm{TMPP})]^{5+}(\mathrm{Mn})$, complex $5(\mathrm{Ni})$, dimethyl sulfate $(\mathrm{G})$ and $[\mathrm{Cu}(\mathrm{phen})]^{2+}(\mathrm{Cu})$.

\section{MECHANISTIC ASPECTS OF SELECTIVE DNA OXIDATION}

\section{Redox potential}

Early indications suggested the importance of the $\mathrm{Ni}^{\mathrm{IIIII}}$ redox couple in DNA reactivity with $\mathrm{KHSO}_{5}$ (ref. 6 and 7). If the redox potential were the predominant factor in determining the extent of reactivity, one would anticipate good correlation between the two. When the percentages of DNA oxidation promoted by nickel(II) tetraazamacrocyclic complexes are arranged in order of increasing redox potential of the complex, the correlation is poor (ref 8). However, when the reactivity of complexes possessing similar ligand donor strength and ligand flexibility are compared, such as 4,7 , and 8 , the extent of DNA oxidation does increase regularly with increasing potential (ref. 8). Also, the DNA reactivity associated with nickel hexamethylcyclam complexes (12-14) were observed to increase with increasing $E_{1 / 2}$ values. However, the reactivity of complexes possessing $E_{1 / 2}$ values greater than $0.92 \mathrm{~V}$ (complexes 11 and 15) was observed to decrease (Fig. 4). Therefore, we conclude that while redox potential is a factor in determining reactivity, other factors such as ligand donor strength and conformational flexibility may predominate.

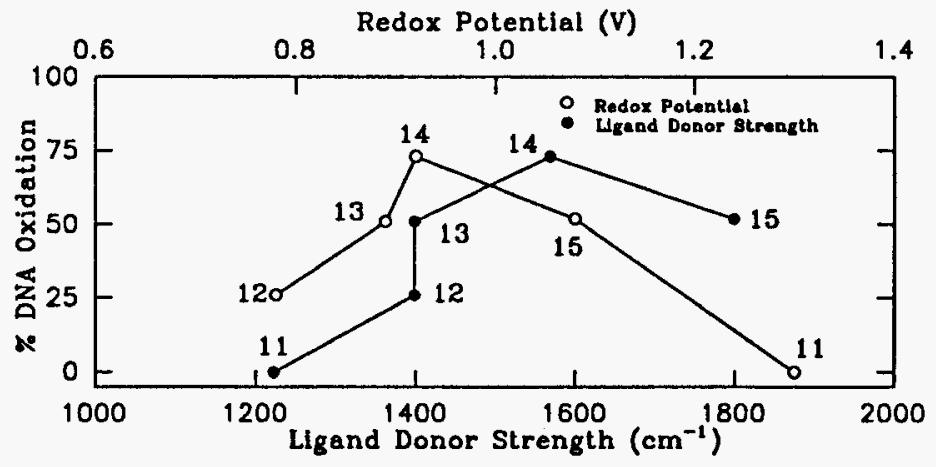

Fig. 4. Percentage of DNA oxidation promoted by complexes 11-15 as a function of redox potential and ligand donor strength.

\section{Ligand donor strength and conformational flexibility}

Direct ligation of a nickel macrocyclic complex to guanine is supported by the high selectivity of nickel complexes for accessible guanine sites in duplex DNA. Furthermore, complexes without vacant coordination sites, such as high spin, octahedral nickel(II) complexes, failed to promote DNA oxidation (ref. 6). To further test the importance of vacant coordination sites, the systematic variation of the ligand donor strengths $\left(\mathrm{Dq}^{x y}\right)$ associated with nickel(II) tetraazamacrocyclic complexes was investigated (ref 8). Busch has previously demonstrated that as the ligand donor strengths of four coordinate nickel(II) macrocyclic ligands increase, the tendency to form an octahedral complex decreases (ref. 14). If the same trend holds true for nickel(III) macrocyclic complexes as for nickel(II), those complexes with a strong $x-y$ ligand field should have more labile $z$ (axial) ligands and therefore should display the greatest ability to interact with DNA. The extent of guaninespecific oxidation of oligonucleotide $\mathbf{D}$ by hexamethylcyclam complexes (11-15) does follow the trend of 
increasing ligand donor strength (Fig. 4), with the exception of complex 15. The observed reduced reactivity in this case might be attributed to the higher rigidity of the macrocyclic ligand making complex 15 less conformationally adaptable for DNA binding. Another unexpected result was observed for complexes 12 and 13 . The ligand field strengths of the two epimeric complexes should be identical, however, their DNA reactivities differ. This difference can again be ascribed to conformational properties.

The dependence upon flexibility of the nickel complex during DNA oxidation may be based upon $(i)$ a slight distortion of the macrocyclic ring to relieve unfavorable steric interactions when the nickel ion binds to DNA or (ii) a more dramatic folding of the ring to a cis geometry. The increased reactivity of complex $13(51 \%)$ as compared to complex 12 (26\%) may be related to differences in flexibility between these two complexes. Based upon extensive structural and reactivity studies, complex 13 has been shown to be capable of folding its macrocyclic ligand leaving vacant two cis coordination sites, while complex 12 cannot easily assume such a conformation because of steric repulsion between the methyl groups (refs. 15-17). For example, 13 readily forms a cis complex with oxalate, whereas 12 can only form highly strained cis complexes (refs. 16 and 17). The decreased reactivity of complex $15(52 \%)$ as compared to complex $14(73 \%)$ may also be attributed to differences in ligand flexibility. The tetraene ligand of complex 15 limits distortion of the macrocyclic ligand from its trans orientation, while the diene ligand present in complex 14 is known to exist in a cis conformation (ref 18).

The results of a systematic investigation of ligand effects further support a proposed mechanism in which the square planar nickel(II) complex is oxidized to a square pyramidal or octahedral nickel(III) complex possessing sufficiently labile axial sites to bind to N7 of guanine (Fig. 5). In addition, flexibility of the macrocyclic ring is important, and would potentially allow formation of a cis-coordinated complex bringing guanine and a bound oxidant into adjacent positions around the metal ion. The postulated mechanism is also supported by the following facts: $(i) \mathrm{KHSO}_{5}$ is a strong oxidant with a potential near $2 \mathrm{~V}$, sufficiently high to cause the oxidation of all the nickel(II) complexes studied, (ii) most nickel(III) polyamine complexes are known to be octahedral, (iii) $\mathrm{N} 7$ of guanine is a known coordination site for nickel, and (iv) electrochemical binding studies with GMP indicate that $\mathrm{K}_{\mathrm{a}}\left(\mathrm{Ni}^{\mathrm{III}}\right) / \mathrm{K}_{\mathrm{a}}\left(\mathrm{Ni}^{\mathrm{II}}\right)$ is 30:1 (ref. 8).

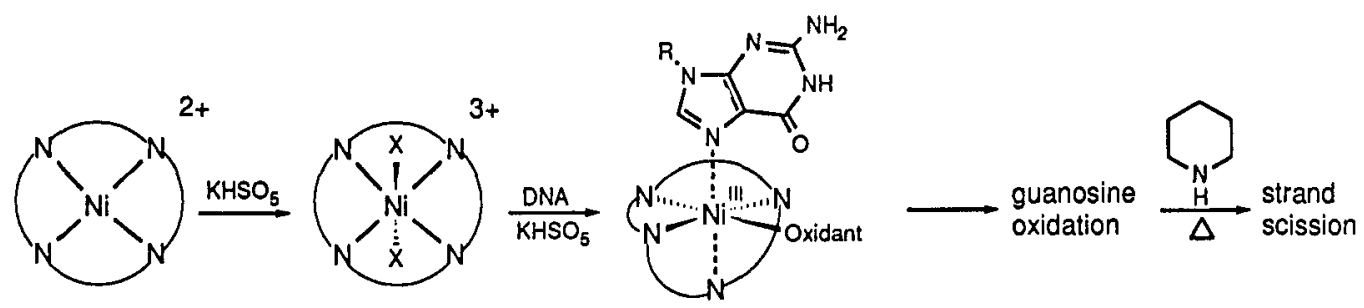

Fig. 5. Proposed reaction mechanism.

\section{Role of the oxidant}

The mechanism depicted in Fig. 5 involves the formation of an octahedral nickel(III) intermediate that contains both a bound guanine residue and an oxidant molecule. The identity of the bound oxidant molecule is not known. However, we suggest that it is $\mathrm{HSO}_{5}{ }^{-}$since sulfate is known to bind and stabilize nickel(III). In order to further identify the reactive intermediate, studies were performed involving the oxidation of oligonucleotide $\mathbf{D}$ by $\left[\mathrm{Ni}(\mathrm{II})\left([14] \mathrm{aneN}_{4}\right)\right]\left(\mathrm{ClO}_{4}\right)_{2}$ (complex 8) or trans-[Ni(III)([14]aneN $\left.\left.\mathrm{N}_{4}\right) \mathrm{Cl}_{2}\right]\left(\mathrm{ClO}_{4}\right)$ and various $1 \mathrm{e}^{-}$and $2 \mathrm{e}^{-}$ oxidants (Table 1). These studies revealed that the single electron transfer $2 \mathrm{e}^{-}$oxidant $\mathrm{K}_{2} \mathrm{~S}_{2} \mathrm{O}_{8}$ and the $1 \mathrm{e}^{-}$ oxidant $\mathrm{Na}_{2} \mathrm{IrCl}_{6}$ were ineffective at promoting the oxidation of DNA, even though the formation of nickel(III) was detected by UV-visible spectroscopy. Additionally, when isolated trans-[Ni(III)([14]aneN $\left.\left.{ }_{4}\right) \mathrm{Cl}_{2}\right]\left(\mathrm{ClO}_{4}\right)$ was used in the absence of an oxidant, no DNA modification was observed. These results indicate that the reactive nickel species responsible for the oxidation of DNA is not simply a nickel(III) complex. $\mathrm{KHSO}_{5}$ and MMPP promoted oxidation in the presence of either $\left[\mathrm{Ni}(\mathrm{II})\left([14] \mathrm{aneN}_{4}\right)\right]\left(\mathrm{ClO}_{4}\right)_{2}$ or trans-[Ni(III) $\left.\left([14] a_{\text {ane }}\right) \mathrm{Cl}_{2}\right]\left(\mathrm{ClO}_{4}\right)$. Therefore, we conclude that only oxidants containing both a ligand (sulfate or carboxylate) for nickel(III) and an oxygen atom donor (peracid) may be effective (Fig. 6). In this regard, peracids could act as bifunctional oxidants reminiscent of that invoked for oxygen's role with bleomycin in which one equivalent is required for activation and a second equivalent is necessary to produce the

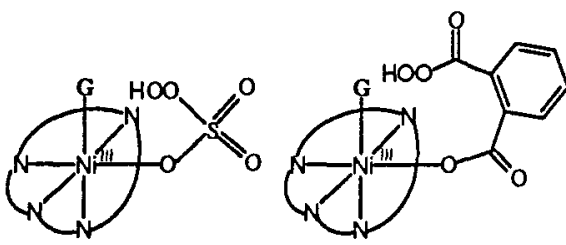

Fig. 6. Proposed intermediates. reactive intermediate (ref. 19). 
Table 1. DNA Reactivity Data for Nickel(II) and Nickel(III) Macrocyclic Complexes."

\begin{tabular}{ccc}
\hline Complex & Oxidant & $\%$ G Oxidation \\
\hline \hline$\left[\mathrm{Ni}(\mathrm{II})\left([14] \mathrm{aneN}_{4}\right)\right]\left(\mathrm{ClO}_{4}\right)_{2}^{\mathrm{c}}$ & $\mathrm{KHSO}_{5}^{\mathrm{d}}$ & 12 \\
$"$ & $\mathrm{MMPP}^{\mathrm{d}}$ & 9 \\
$"$ & $\mathrm{~K}_{2} \mathrm{~S}_{2} \mathrm{O}_{8}^{\mathrm{d}}$ & 1 \\
trans-[Ni $\left.(\mathrm{III})\left([14] \mathrm{NaneN}_{4}\right) \mathrm{Cl}_{2}\right]\left(\mathrm{ClO}_{4}\right)^{\mathrm{c}}$ & $\mathrm{Na}_{2} \mathrm{ICl}_{6}^{\mathrm{e}}$ & 0 \\
& none & 0 \\
$"$ & $\mathrm{KHSO}_{5}^{\mathrm{d}}$ & 11 \\
$"$ & $\mathrm{MMPP}^{\mathrm{d}}$ & 9 \\
$"$ & $\mathrm{~K}_{2} \mathrm{~S}_{2} \mathrm{O}_{8}^{\mathrm{d}}$ & 0 \\
& $\mathrm{Na}_{2} \mathrm{IrCl}_{6}^{\mathrm{e}}$ & 0 \\
\hline
\end{tabular}

a. Experimental conditions are described in ref. 8 b. Percentage of DNA oxidation as calculated from the ratio of radioactivity above background associated with the oxidation of $\mathrm{G}_{8}, \mathrm{G}_{9}, \mathrm{G}_{10}$ versus the total radioactivity. c. Concentration: $6.0 \mu \mathrm{M}$

d. Concentration: $120 \mu \mathrm{M}$. e. Concentration: $240 \mu \mathrm{M}$.

\section{Effect of the transition metal atom}

In order to investigate the function of the central metal atom associated with the oxidation of DNA by nickel complexes, a series of transition metal complexes containing [14]ane $\mathrm{N}_{4}$ (cyclam) were tested as potential DNA modifying agents. When the hairpin oligonucleotide $\mathrm{D}(3.0 \mu \mathrm{M})$ was treated with $\mathrm{KHSO}_{5}(120 \mu \mathrm{M})$ and a series of metal complexes $(6.0 \mu \mathrm{M})$, trans-[Co(III) $[14]$ ane $\left.\mathrm{N}_{4} \mathrm{Cl}_{2}\right]^{+}$, trans-[Rh(III) $\left.[14] \mathrm{aneN}_{4} \mathrm{Cl}_{2}\right]^{+}$and cis[Cr(III)[14]ane $\left.\mathrm{N}_{4} \mathrm{Cl}_{2}\right]^{+}$displayed oxidation significantly above background (Fig. 7). Conversely, trans[Mn(III)[14]ane $\left.\mathrm{N}_{4} \mathrm{Cl}_{2}\right]^{+}, c i s-\left[\mathrm{Fe}(\mathrm{III})[14] \mathrm{aneN}_{4} \mathrm{Cl}_{2}\right]^{+}$, and [Cu(II)[14]ane $\left.\mathrm{N}_{4}\right]^{2+}$ displayed little or no tendency towards DNA oxidation (Fig. 7). Since copper(II) and copper(III) complexes generally display very little tendency towards axial ligation (ref. 20) the inactivity of $\left[\mathrm{Cu}(\mathrm{II})[14] \text { ane } \mathrm{N}_{4}\right]^{2+}$ is consistent with the proposed mechanism depicted in Fig. 5. However, it is somewhat surprising that neither trans-[Mn(III)[14]ane $\left.\mathrm{N}_{4} \mathrm{Cl}_{2}\right]^{+}$nor cis-[Fe(III)[14]ane $\left.{ }_{4} \mathrm{Cl}_{2}\right]^{+}$reacted with DNA especially when considering that $\left[\mathrm{Fe}(\mathrm{II})[14] \mathrm{aneN}_{4}\right]^{2+}(\mathrm{ref} .21)$ is a known epoxidation catalyst and [Mn(TMPP) $]^{5+}$ is known to oxidize DNA. The inactivity of cis[Fe(III) [14]ane $\left.\mathrm{N}_{4} \mathrm{Cl}_{2}\right]^{+}$may be related to the reported propensity of iron(III) macrocyclic complexes to decompose, particularly in the presence of water (ref. 22). In the case of trans-[Mn(III)[14]ane $\left.\mathrm{N}_{4} \mathrm{Cl}_{2}\right]^{+}$, the inactivity towards DNA oxidation may be associated with the fact that, unlike [Mn(TMPP) $]^{5+}$, this manganese complex does not contain ligands which are capable of forming electrostatic or intercalative interactions with DNA.

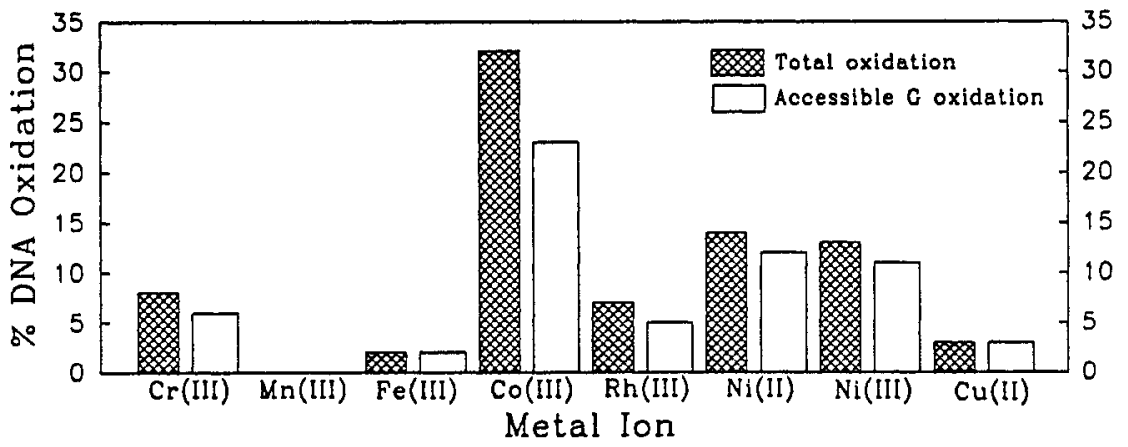

Fig. 7. Comparison of the DNA reactivity of transition metal cyclam complexes.

The order of reactivity associated with the metal complexes that display significant activity towards DNA oxidation was found to be: $\mathrm{Co}(\mathrm{III})>\mathrm{Ni}$ (II) $-\mathrm{Ni}(\mathrm{III})>\mathrm{Rh}(\mathrm{III}) \sim \mathrm{Cr}$ (III) (Fig. 7). The ability of $\mathrm{Co}$ (III) and $\mathrm{Rh}$ (III) complexes to induce the guanine-specific oxidation of oligonucleotide $\mathbf{D}$ is consistent with the observed binding of guanosine (or deoxyguanosine) to cobalt(III) and rhodium(III) polyamine complexes (refs. 23 and 24) and the observed guanine-specific oxidation of DNA by cobalt(II) ions and hydrogen peroxide (ref. 25). A proposed cobalt(III) intermediate, analogous to nickel, containing a coordinated peracid is also consistent with the fact that cobalt(III) alkylperoxy complexes are known to induce the oxidation of organic substrates (ref. 26). If the oxidation of DNA by cobalt(III) and rhodium(III) involves direct ligation of guanine to the central metal 
atom, the decrease in activity of trans-[Rh(III)[14]ane $\left.\mathrm{N}_{4} \mathrm{Cl}_{2}\right]^{+}(7 \%)$, as compared to trans-[Co(III)[14]ane $\left.\mathrm{N}_{4} \mathrm{Cl}_{2}\right]^{+}$ (32\%), would be consistent with the known decrease in the tendency of thodium(III) complexes to undergo ligand substitution relative to cobalt(III) complexes (ref. 27). Finally, since chromium(V) oxo DNA modification agents are believed to form Cr-DNA species prior to oxidation (ref. 28), a reaction mechanism analogous to that depicted in Fig. 5 involving a chromium(V) oxo species may explain the observed reactivity of cis[Cr(III) $[14]$ ane $\left.{ }_{4} \mathrm{Cl}_{2}\right]^{+}$.

\section{CONCLUSIONS}

Nickel(II) complexes containing tetraazamacrocyclic ligands were shown to promote the oxidation of DNA at accessible guanine residues using $\mathrm{KHSO}_{5}$ or MMPP as the oxidant. The study of oligonucleotide models established that nickel(II) macrocyclic complexes are very useful DNA conformational probes. This in turn suggests a mechanism for reaction involving ligation of a nickel(III) species to N7 of guanine. The conformation-specific oxidation of DNA by nickel complexes was not duplicated by other previously reported DNA modification agents. The systematic study of ligand effects revealed that nickel(II) macrocyclic complexes that are sufficiently flexible and possess a strong in-plane donor ligand display the greatest ability to oxidize DNA. Additionally, ligand effect and oxidant dependence studies support a proposed mechanism involving a nickel(III) intermediate containing a coordinated guanine and oxidant molecule. Finally, the oxidation of DNA has been extended to macrocyclic complexes containing cobalt(III), rhodium(III) and chromium(III). These metal complexes are believed to follow a similar reaction mechanism to the one proposed for nickel(II) complexes.

\section{Acknowledgment}

Support of this work through a Seed Grant from the Stony Brook Center for Biotechnology sponsored by the New York State Science and Technology Foundation (to S. E. R. and C. J. B.), a grant (to C. J. B.) from the National Science Foundation (CHE-9006684), and a Postdoctoral Fellowship (to J. G. M.) from the American Cancer Society is gratefully acknowledged.

\section{REFERENCES}

1. T.D. Tullius, Ed, Metal-DNA Chemistry; ACS Symposium Series 402, American Chemical Society, Washington, DC (1989).

2. A.M. Pyle and J.K. Barton, Prog. Inorg. Chem. 38, 413-475 (1990).

3. D.P. Mack and P.B. Dervan, J. Am. Chem. Soc. 112, 4604-4606 (1990).

4. S.J. Lippard, Pure Appl. Chem. 59, $731-742$ (1987).

5. M. Green, M. Garner and D.M. Orton, Transition Met. Chem. 17, 164-176 (1992).

6. X. Chen, S.E. Rokita and C.J. Burrows, J. Am. Chem. Soc. 113, 5884-5886 (1991).

7. X. Chen, C.J. Burrows and S.E. Rokita, J. Am. Chem. Soc. 114, 322-325 (1992).

8. J.G. Muller, X. Chen, A.C. Dadiz, S. E. Rokita and C.J. Burrows, J. Am. Chem. Soc. 114, 6407-6411 (1992).

9. T.D. Tullius, Metal-DNA Chemistry; ACS Symposium Series 402, T.D. Tullius, Ed., p. 1-23, American Chemical Society, Washington, DC (1989).

10. R.B. Van Atta, J. Bernadou, B. Meunier and S.M. Hecht, Biochemistry 29, 4783-4789 (1990).

11. D.S. Sigman and C.H.B. Chen, Metal-DNA Chemistry; ACS Symposium Series 402, T.D. Tullius, Ed., p. 24-47, American Chemical Society, Washington, DC (1989).

12. H.R. Drew, J. Mol. Biol., 176, 535-557 (1984).

13. A.M. Maxam and W. Gilbert, Methods Enzymol. 65, 499-560 (1980).

14. L.Y. Martin, R. Sperati and D.H. Busch, J. Am. Chem. Soc. 99, 2968-2981 (1977).

15. L.G. Warner and D.H. Busch J. Am. Chem. Soc. 91, 4092-4101 (1969).

16. P.O. Whimp, M.F. Bailey and N.F. Curtis J. Chem. Soc. (A) 1956-1963 (1970)

17. N.F. Curtis, D.A. Swann and T.N. Waters, J. Chem. Soc. Dalton Trans. 1408-1413 (1973).

18. N.F. Curtis, J. Chem. Soc. $4109-4115$ (1963).

19. J. Stubbe and J.W. Kozarich, Chem. Rev. 87, 1107-1136 (1987).

20. N.N. Greenwood and A. Eamshaw, Chemistry of the Elements, p. 1379, Pergamon Press, New York (1984).

21. W. Nam, R. Ho and J.S. Valentine, J. Am. Chem. Soc. 113, 7052-7054 (1991).

22. V.L. Goedken, P.H. Merrell and D.H. Busch J. Am. Chem. Soc. 94, 3397-3405 (1972).

23. L.G. Marzilli, T.J. Kistenmacher, P.E. Darcy, D.J. Szalda and M. Beer, J. Am. Chem. Soc. 96, 4686-4688 (1974),

24. L.M. Torres and L.G. Marzilli, J. Am. Chem. Soc. 113, 4678-4679 (1991).

25. K. Yamamoto, S. Inoue, A. Yamazaki, T. Yoshinaga and S. Kawanishi, Chem. Res. Toxicol. 2, 234-239 (1989).

26. L. Saussine, E. Brazi, A. Robine, H. Mimoun, J. Fischer and R. Weiss, J. Am. Chem. Soc. 107, 3534-3540 (1985).

27. M.L. Tobe, Inorganic Reaction Mechanisms, p. 87, Thomas Nelson and Sons Ltd, London (1972).

28. R.P. Farrell, R.J. Judd, P.A. Lay, N.E. Nixon, R.S.U. Baker and A.M. Bonin, Chem. Res. Toxicol. 2 , 227-229 (1989). 